\title{
Research on Secondary Impact Safety of Train Driver based on THUMS Dummy
}

\author{
Wenbin Wang ${ }^{1}$, Jiawei $\mathrm{Ji}^{1}$, Zhitao Yue ${ }^{1}$, Dongdong Zhang ${ }^{1}$, Honglei Tian ${ }^{2}$ and Hongwei Zhao ${ }^{2}$ \\ ${ }^{1}$ Institute of Rail Transit, Tongji University, Shanghai, China \\ ${ }^{2} R \& D$ Center, CRRC Qingdao Sifang Co., Ltd Qingdao, China
}

\begin{abstract}
Based on biomechanical Total Human Model for Safety (THUMS) dummy and traditional rigid dummy, the train driver injury of secondary impact in railway crash events is analyzed and the results are compared. The results of THUMS dummy are more detail and comprehensive to describe the injury of train driver. It could be applied to the safety research of crashworthiness of train driver cab in future. The driver injury is serious and needed to be optimized the parameter of cab console to reduce injury risk for the driver in the next work.
\end{abstract}

\section{Introduction}

The injury of occupant is very serious in railway crash events, especially for the train driver. There are two main reasons. Firstly, the driver has got injured at the front zone of train. The large plastic deformation will be occurred at the train cab after the train collision and the survival space will be squeezed seriously. Secondly, owing to complicated interior structure of railway cab, the driver could be injury by interior decoration during secondary impact.

Research on railway vehicle crashworthy and occupant secondary impact safety has been developed for many years, and lots of achievements are made [1]-[7]. For example, British Rail developed a series of studies on secondary impact of occupant and passenger compartment structures, and drew up the crashworthiness for interior trim structures in vehicle and devised occupant protection standard AV/ST9001 [8]-[11]. The Volpe National Transportation Systems Center combined a number of tests with non-linear finite element simulations to research crashworthiness of railway vehicle and the occupant injury impacted with interior structure [12]-]=15]. The Japan Railway Technical Research Centre applied multibody dynamics dummy to research secondary impact in subway [16]. However, the injury of train driver based on THUMS dummy is researched rarely at present.

In this paper, the train driver injury during secondary impact is researched based on THUMS dummy with the more detail and comprehensive injury index by THUMS.

\section{Models and methods}

\subsection{Models}

THUMS dummy model is developed by Japan's Toyota motor company (Fig. 1). All organs and skeletons are modeled to simulate body responses in crash. The injury index is more detail and reasonable than the traditional rigid dummy. So THUMS dummy is used in this research to improve some designs of structure and reduce injury of train driver in crash simulation.

The cab console is mainly made up of the equipment cabinet, the driver panel, the pedal and so on. Considering complicated structure, the model is simplified. A lot of equipments which have no effect on secondary impact are omitted (Fig. 2).

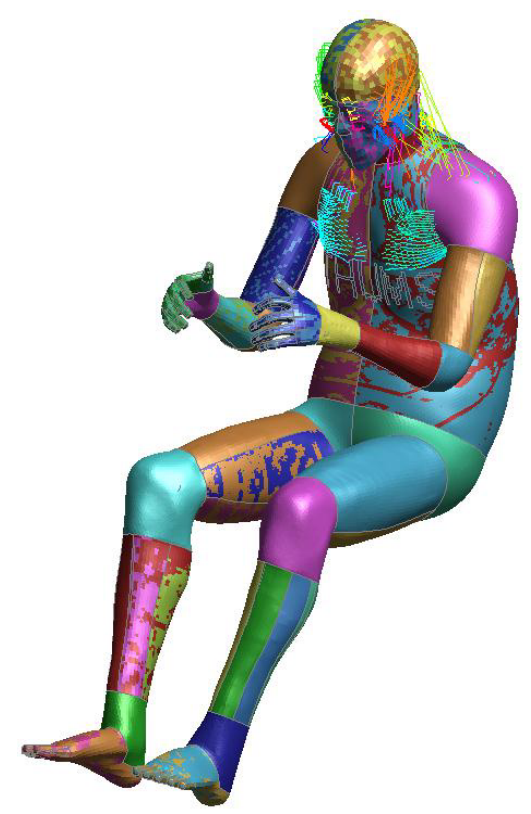

Figure 1. THUMS 50 percentile occupant dummy. 


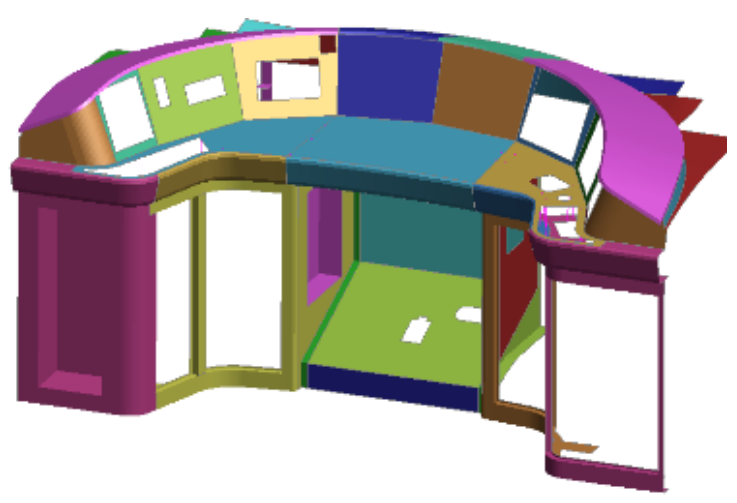

Figure 2. The finite element model of console.

\subsection{Evaluation standard of biomechanical dummy}

THUMS dummy model, which simulates human Biomechanical response, has a separate index evaluation system. A body or a part, an organ or a tissue under dynamic loads associated with the mechanical properties of the time is called biomechanical response. Not only to consider the stress and deformation of human organs but also physiological changes, such as pain, edema and arrhythmia. Recommended values of Human various organs and tissue damage are shown in Table 1.

Table1. Recommended values of human various organs and tissue damage.

\begin{tabular}{|c|c|c|}
\hline Index & Strain & Stress \\
\hline Brain tissue damage & 0.21 & $\pm 230 \mathrm{kPa}$ \\
\hline Fracture & $3 \%$ & $*$ \\
\hline Ligament & $11 \%$ & $*$ \\
\hline Lung damage & $*$ & $\pm 10 \mathrm{kPa}$ \\
\hline Heart tissue damage & $30 \%$ & $*$ \\
\hline Liver & $30 \%$ & $*$ \\
\hline Kidney & $30 \%$ & $*$ \\
\hline Spleen & $30 \%$ & $*$ \\
\hline Small intestine & $120 \%$ & $*$ \\
\hline Chest and blood vessels & $100 \%$ & $*$ \\
\hline
\end{tabular}

\section{Working conditions and results}

To make simulation results of the cab occupant more accurately reflecting human injury in secondary collision, THUMS dummy is applied to simulate cab occupant secondary impact damage, and compared the simulation results with the rigid dummy.

\subsection{Working conditions}

THUMS dummy and traditional rigid dummy sitting position are shown in figure 3. The same working conditions are set for both. Boundary condition is the triangular impact acceleration curve and the initial speed is $36 \mathrm{~km} / \mathrm{h}$ [14-15].

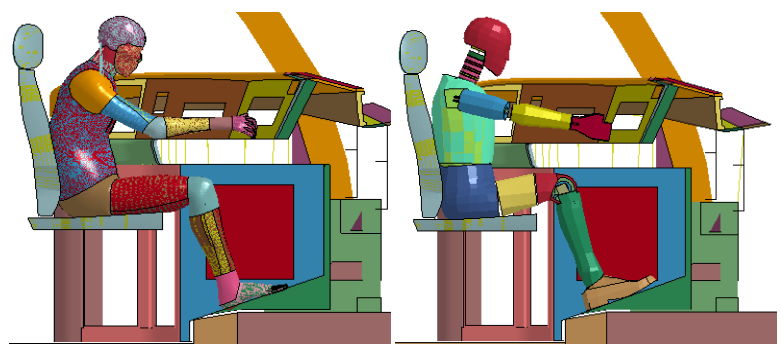

Figure 3. THUMS dummy and traditional rigid dummy.

\subsection{Analysis of motion state}

Dummy motions are shown in Fig. 4(a, b, c), when the collision time is $0.119 \mathrm{~s}$, THUMS dummy upper body including waist, hips and thigh section slides forward on the seat, and the abdomen and console bulkhead crashes. When the collision time is $0.161 \mathrm{~s}$, THUMS dummy's amount of compression of chest and abdomen reach the maximum and begin to recover slowly. The head started to move downward. The arm is supported on the console panel. Thigh and the lower surface of the console spacer is bonded tightly together. When the collision time is $0.225 \mathrm{~s}$, most abdominal compression of THUMS dummy has been restored, there is no contact with the console separator for head.

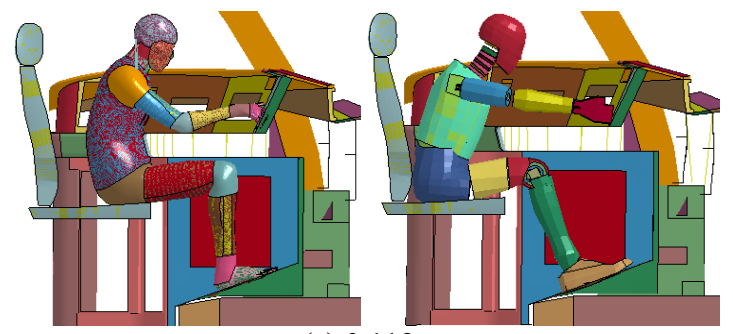

(a) $0.119 \mathrm{~s}$

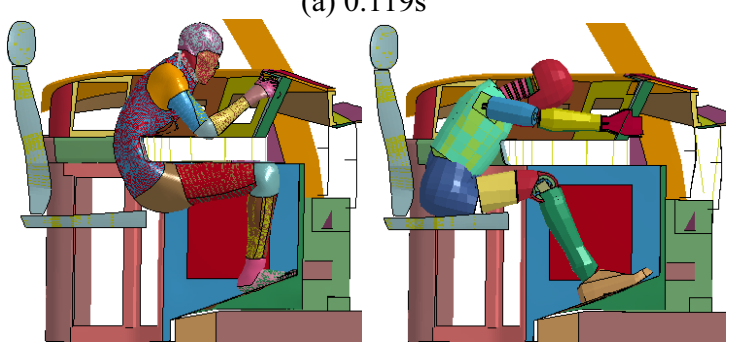

(b) $0.161 \mathrm{~s}$

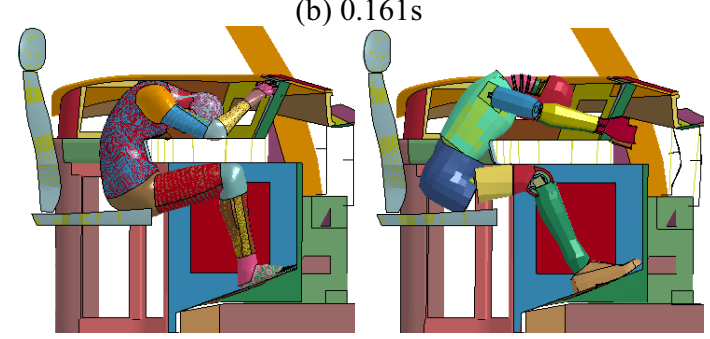

(c) $0.225 \mathrm{~s}$

Figure 4. The motion state of THUMS and rigid dummy.

As is shown in Fig. 5, Motion state of dummy is different. THUMS dummy thoracic and abdominal compression is larger than the rigid dummy. The THUMS dummy is softer and more accurate than rigid dummy. The contact force between the console and dummy is shown in Fig. 6. The contact force of THUMS dummy 
and the console is $14.9 \mathrm{kN}$. However, the contact force of rigid dummy is only $4 \mathrm{kN}$. Due to the different movement condition of THUMS dummy and rigid dummy, the two results are different because of the different contact part.
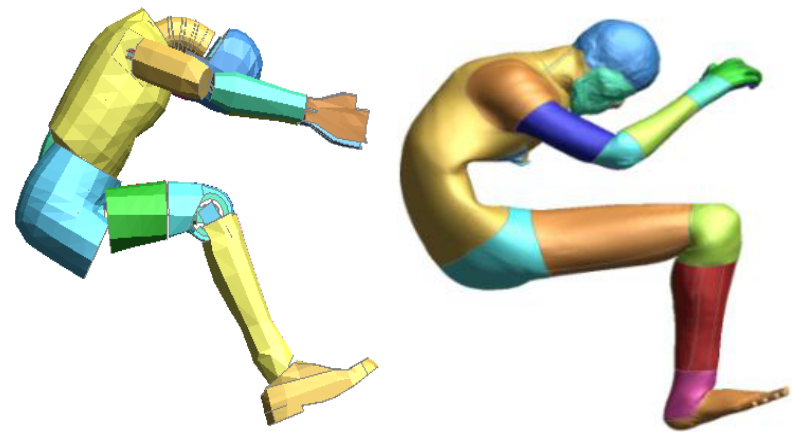

Figure 5. Deformation of dummy.

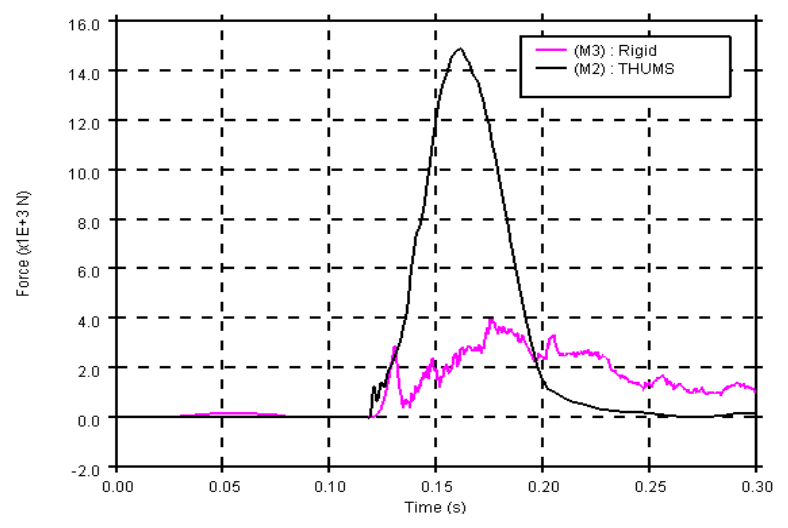

Figure 6. Curve of contact force.

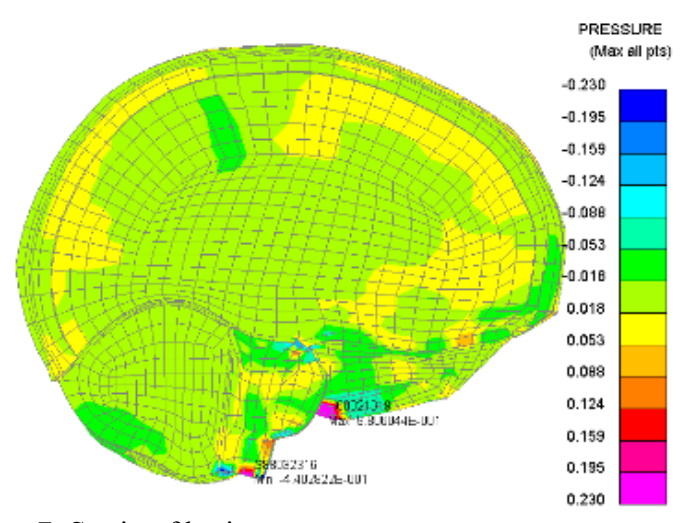

Figure 7. Strain of brain

\subsection{Analysis of THUMS dummy damage}

\subsubsection{Head damage}

The strain and stress of THUMS dummy brain injury are shown in Fig. 7 and Fig. 8. The maximum strain value of brain is 0.572 , which exceeded the limited value 0.21 . The maximum stress value of head is $232 \mathrm{kPa}$, slightly larger than $230 \mathrm{kPa}$.

The acceleration is shown in Fig. 9. HIC15 of THUMS dummy brain is 3045 (center) and 251 (near the eye). There is huge difference at the different part of brain. So HIC index is not suitable for the THUMS brain damage. HIC15 of general rigid dummy brain is 195, almost same as the eye point of THUMS brain.

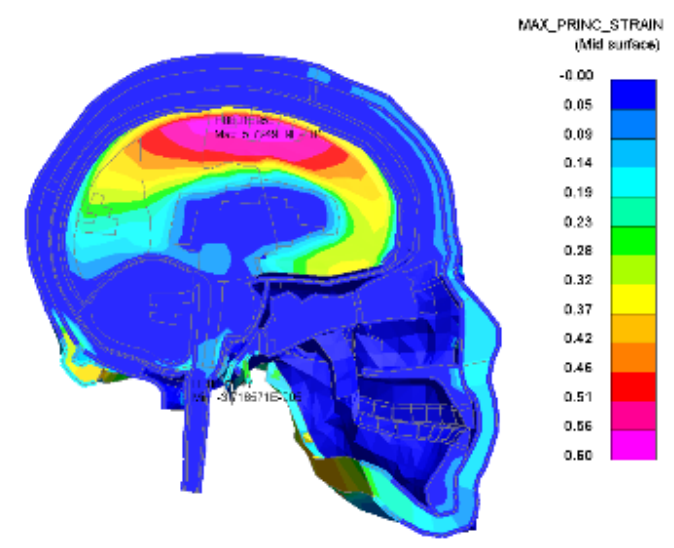

Figure 8. Stress of brain

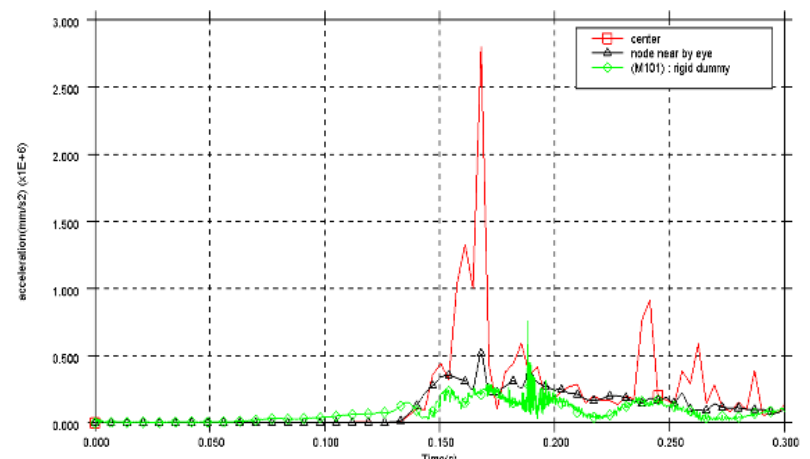

Figure 9. Head acceleration of THUMS and rigid dummy.

\subsubsection{Chest and abdomen damage}

THUMS dummy chest has three fractures (figure 10). Fractured ribs easily pierced soft tissue into the lungs, which resulted in haemothorax, pneumothorax and other serious injury. According to the result, most of ribs are very dangerous. The ligament bends seriously and is out of shape (Fig. 11). The maximum value of ligament strain is 1.7 , which surpassed the limited value greatly. So, the possibility of the ligament injured is very large. The compression quantity of chest is shown in Fig. 12, the maximum of which is about $45 \mathrm{~mm}$.

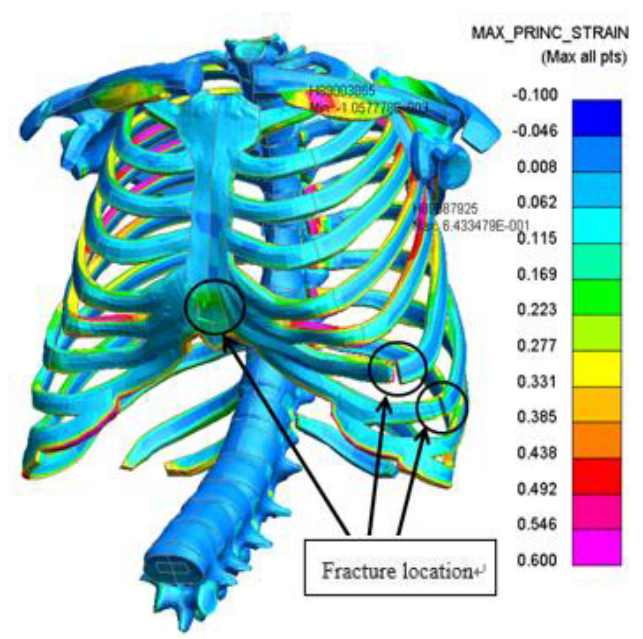

Figure 10. Strain of ribs 


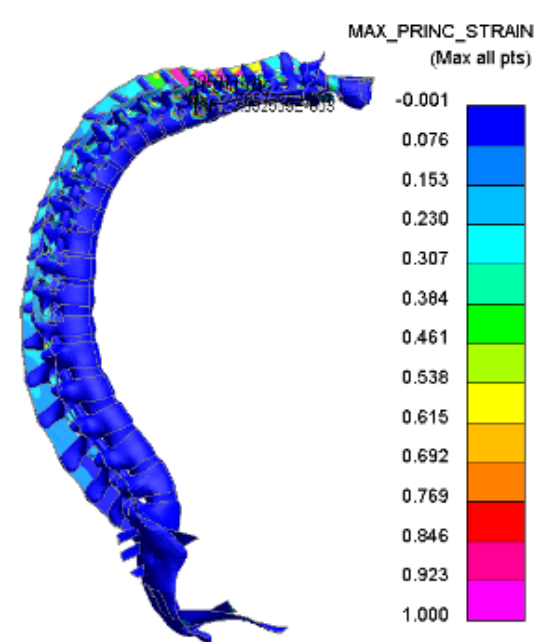

Figure 11. Strain of ligament

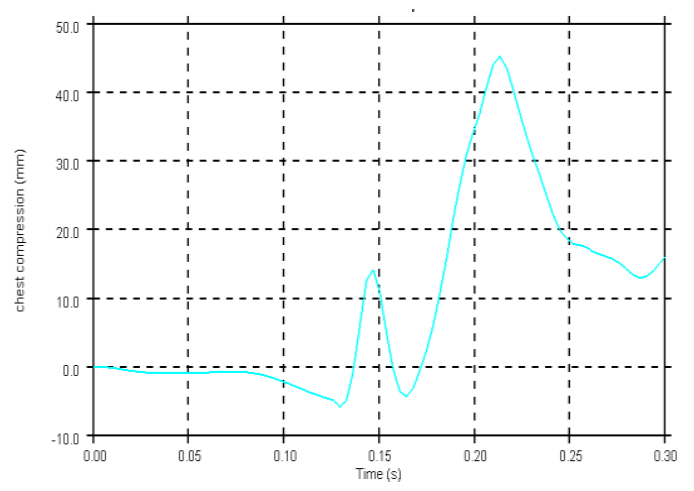

Figure 12. Compression quantity of Chest.

In secondary impact, abdominal diaphragm is squeezed by the console plate. Liver moved up because abdominal muscle tissue squeezed it. In addition, lung, heart and blood vessels are also squeezed in different extent. Nevertheless, the middle and lower part of abdomen is most serious among them.

The stress of lung is shown in Fig. 13. The maximum stress value of lung is $454 \mathrm{kPa}$ and the minimum is $178 \mathrm{kPa}$, which is beyond the recommendation value $\pm 10 \mathrm{kPa}$, as shown in Table1. It resulted in pneumothorax and deadly injury possibly.

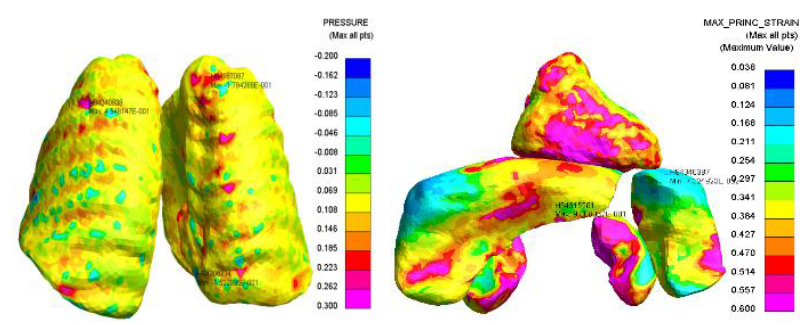

Figure 13. Lung stress Figure 14. Abdomen' organs strain

As shown in Fig. 14, most part of the heart, liver, spleen, and kidney strain are around $30 \%$. The maximum strain of heart is 0.635 , two times of allowable value. Heart is squeezed, and has the risk of myocardial tissue torn. It is also possible to cause blood to enter the blood vessels, which caused the rupture of the aorta. The maximum strain of liver tissue is 0.98 , and the tissue may be torn, which caused the injury of liver. The maximum strain of the spleen is 0.673 , which is also beyond the allowable value. The maximum strain of the kidney is 0.836 , which is above the limit of 0.3 .

The blood vessels of the human body have blood flow, especially the effect of the blood flow of the heart pump. The expansion rate is larger, and the strain limit is $100 \%$. Similarly there is liquid diet in gastrointestinal tract. Especially the small intestine deep-rooted is very soft and flabby, and the damaged strain is $120 \%$. The injury of the blood vessel and the digestive tract is shown in figure 15 . The maximum strain in the small intestine is $177 \%$, which is above $120 \%$. So, it may appear small intestinal laceration, intestinal bleeding and other damage. The major blood vessels in the chest and abdomen are basically less than $100 \%$, and the blood vessels are less damaged.

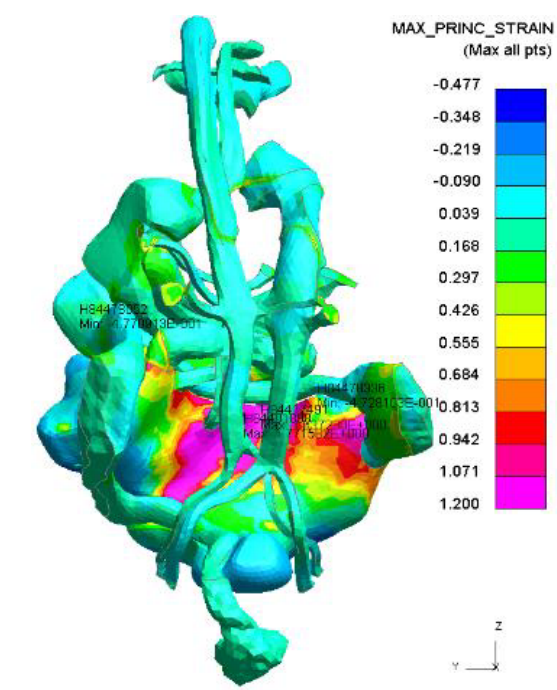

Figure 15. Strain of blood vessels and digestive system.

Simulation results showed that the THUMS dummy has lots of injuries including diffuse contusion of brain, three fractures, hemothorax, pneumothorax, different damage of internal organs and avulsion injury in the intestines. It could be determined that the wounded need emergency treatment.

Comparing with the general rigid dummy, more simulate results, such as the deformation of the skeleton, the strain of the internal organs and the damage of blood vessels can be gotten with THUMS dummy. The simulation results are more realistic than general rigid dummy. It is proposed that in the future study, THUMS dummy should be used widely in train occupant safety simulation.

From the simulation results shown, the injury is serious. The key interior part- cab console should be optimized to reduce injury risk for the driver secondary impact in the future work.

\section{Conclusions}

This paper describes the application of THUMS dummy in train driver secondary impact. Comparing the simulation result of THUMS dummy and the general rigid dummy, it is proved that the damage of THUMS is 
more detail and comprehensive in secondary impact simulation. THUMS dummy could be applied to the safety research of crashworthiness of train driver cab in the future work.

\section{Acknowledgements}

The authors would like to thank the Ministry of Science and Technology of China, the research work presented has been substantially supported by the project "The key technology research of next generation metro train and the prototype manufacture" (project No.2015BAG12B01).

\section{References}

1. Sutton A, "The development of rail vehicle crashworthiness," IMechE, Part F, vol. 216, 97-108 (2002)

2. Wang Wenbin, Kangkang, Zhao Honglun. Joint simulation of crashworthy train set based on nonlinear finite element and multi-body dynamic. Journal of Tongji University, vol.39, 1552-1556 (2011)

3. Wang, Wenbin. The Crashworthiness Design of Railway Vehicle and Passive Safety of Occupant. Doctoral Dissertation, Tongji University, Shanghai, (2006)

4. Hechao Zhou, Wenbin Wang, Markus Hecht. Threedimensional override analysis of crashed railway multiple units .Vehicle System Dynamics, vol.50, 663-674 (2012)

5. Hechao Zhou, Wenbin Wang, Markus Hecht. Threedimensional derailment analysis of a crashed city tram, Vehicle System Dynamics, vol.51,1200-1215 (2013)

6. Xie SC, Tian HQ. Dynamic simulation of railway vehicle occupants under secondary impact. Vehicle System Dynamics. Vol.51, 1803-1817 (2013)
7. Hyung-Suk Han, Jeong-Seo Koo, "Simulation of Train Crashes in Three Dimensions", Vehicle System Dynamics, vol. 40, 435-450 (2003)

8. Lu G, "Energy absorption requirement for crashworthy vehicles," IMechE ,Part F, vol. 216, 3139 (2002)

9. Xue X, Schmid F, Smith RA. A study of modelling approaches for rail vehicle collision behavior. International Journal of Crashworthiness, vol.9, 515525 (2004)

10. ATOC. Vehicle interior crashworthiness. AV/ST9001. London, (2002)

11. European Standard EN 15227:2010. Railway applications-Crashworthiness requirements for railway vehicle bodies, (2010)

12. Tyrell David, "US rail equipment crashworthiness standards," IMechE, Part F, vol. 216, 123-130 (2002)

13. Tyrell David, "Rail passenger equipment accidents and the evaluation of crashworthiness strategies," IMechE, Part F, vol. 216, 131-147 (2002)

14. Kristine,Severson. Research and Development of A Safety Standard for A Safety standard for Workstation Tables in the United States. Proceeding of International Symposium on Passive Safety of Rail Vehicle, Berlin, 107-121 (2013)

15. Tyrell DC. US rail equipment crashworthiness standards. Proc Inst Mech Eng F, J Rail Rapid Transit. vol.216, 123-130 (2002)

16. oão F. Milho, Jorge A.C. Ambrósio \& Manuel F.O.S. Pereira .A multibody methodology for the design of anti-climber devices for train crashworthiness simulation, International Journal of Crashworthiness, vol.7, 7-20 (2002) 